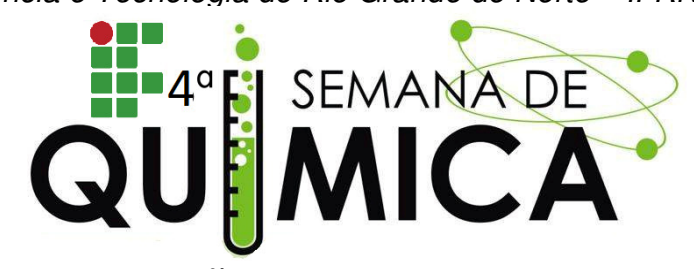

\title{
IDENTIFICAÇÃO E QUANTIFICAÇÃO DE TANINOS NA CASCA DE CAJUEIRO PELA ESPECTROSCOPIA DO UV-VISIVEL
}

Autores: OLIVEIRA, V.L(IFRN); SANTOS. J. A. N.(IFRN); JÚNIOR, J. C. A. V.(IFRN); MEDEIROS, J. V. S.(IFRN);

Palavras Chave: Tanino, Anti-inflamatório, Espectrofotometria.

NTRODUÇÃO:

Ao longo dos anos os estudos sobre taninos e outros espécies criaram uma ferramenta para a ciência na busca por substâncias que possam ser ponto de partida para o desenvolvimento de fármacos. Os taninos são classificados em hidrolisáveis e condensados. Os primeiros são constituídos por diversas moléculas de ácidos fenólicos, como o gálico.nOs taninos condensados incluem todos os outros taninos verdadeiros, as moléculas são mais resistentes à fragmentação e estão relacionadas com flavonoides, tendo uma estrutura "polimérica" do flavan3ol, como a catequina. Então esses extratos podem ser usados para tratamentos de doenças obedecendo é claro adequada e tempo controlado

\section{METODOLOGIA}

Os extratos foram obtidos a partir de casca do cajueiro, que foram secas,trituradas e colocadas em repouso com água destilada durante 3 dias e depois foi filtrada. Posteriormente realizamos as análise de $\mathrm{pH}$ (digital OAKTON, da Eutech Instruments), turbidez(turbidímetro de bancada Tecnopon, versão 4.0), condutividade(de bancada, modelo: DDS, microprocessor) e Teor de taninos no espectrofotômetro( Spectro Vision SB1810S) na região do Uv- Visível. O padrão usado na curva de calibração foi o fenol mas o ideal seria o ácido gálico.

RESULTADOS E DISCUSSÕES

Tabela 1 - Resultados das análises

\begin{tabular}{|c|c|c|c|c|}
\hline $\begin{array}{l}\text { Amostr } \\
\text { a }\end{array}$ & pH & Turbidez & Condutância & $\begin{array}{c}\text { Teor de } \\
\text { Tanino }\end{array}$ \\
\hline $\begin{array}{c}\text { Casca } \\
\text { de }\end{array}$ & $\begin{array}{c}4,8 \\
\text { Cajueiro }\end{array}$ & $\begin{array}{c}4,16 \\
\text { NTU }\end{array}$ & $\begin{array}{c}145,4 \mu \mathrm{S} \\
23^{\circ} \mathrm{C}\end{array}$ & $\begin{array}{c}283,71 \\
\mathrm{mg} / \mathrm{L}\end{array}$ \\
\hline
\end{tabular}

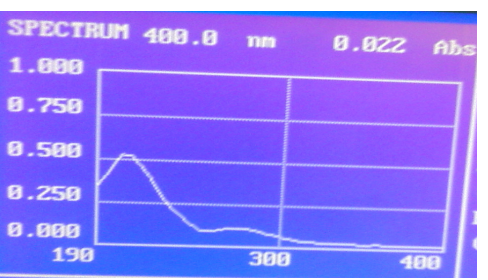

Figura1:Espectro do extrato

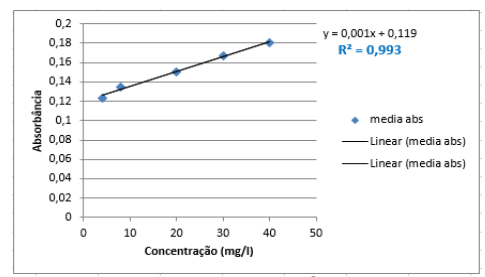

Figura2:Coeficiente $\mathrm{R}^{2}$

Esse $\mathrm{pH}$ é baixo devido aos ácidos fenólicos, como o gálico. A condutividade dessa amostra é devido a ionização dos ácidos (gálico, clorogênico e o elágico) e sais. Na turbidez encontramos um valor baixo, apesar do extrato ter coloração avermelha, sendo essa cor atribuída a os pigmentos flavonoides, tendo uma estrutura "polimérica" após tratamentos com ácidos formando as flobafenos. Essa concentração de taninos esta próxima dos citados na literatura com outras espécies, temos uma linearidade e confiabilidade dos resultados encontrados confirmados pelo coeficiente de correlação.

\section{CONCLUSÃO}

Concluímos que a espectrofotometria no UVVisível apresenta a importante vantagem de ser uma técnica simples, rápida, de baixo custo e que utiliza menos quantidade de solvente em comparação à CLAE, conclui-se que o método, conforme descrito neste trabalho, pode ser uma alternativa para a quantificação de taninos no extrato da casca de cajueiro.

REFERÊNCIAS

Miller JN, Miller JC 2002. Estadística yQuimiometría para Química Analítica. Madrid: Pearson Educación S.A.

FALCÃO, H. S.; et al. Review of the plants with antiinflammatory activity studied in Brazil. Revista

Brasileira de Farmacognnosia, v. 15, p. 381-391, 2005. 